more if it had included more thorough presentations and discussions of the parallel development of ecology. Surely the philosophy of Smuts lives on in ecology today (as holistic or system-orientated ecology), especially among those who share his vision of an integrated organic world in which there is a natural harmony disturbed primarily by humans. But the mechanistic equilibrium position corresponding to the development of population and community intrinsic feedback interactions is currently the dominating one - not least because it pays proper attention to darwinian evolution.

Perhaps if this book had been written by practising ecologists with proper training in the history of science, or by a historian trained in ecology, it might have covered the ideological and subject-based conceptual issues in a more balanced way.

Nils Chr. Stenseth is in the Department of Biology, University of Oslo, $\mathrm{N}-0316$ Oslo,

Norway; Michael Ruse is in the Department of

Philosophy, Florida State University, Tallahassee, Florida 32306, USA.

\section{Bringing speciation to the surface}

\section{Adaptive Radiation of Blind Subterranean Mole Rats \\ by E. Nevo, E. Ivanitskaya \& A. Beiles Backhuys:2001. 200 pp. 37 euros}

\section{Ernst Mayr}

The blind subterranean mole rat of the Near East, around the eastern Mediterranean, is an extraordinary taxonomic phenomenon. It was first thought to be a geographically variable single species (Spalax ehrenbergi) with local subspecies and karyotypes. But then it was discovered that this set of populations is a compound 'superspecies' of 12 allospecies, each occupying a geographically distinct region, which makes it unique among terrestrial vertebrates. When two of these allospecies meet, they interbreed to form a narrow hybrid belt. But the $\mathrm{F}_{1}$ hybrids do not interbreed with the parent allospecies (backcrossing). The range of $S$. ehrenbergi (sensu lato) is therefore a mosaic of 12 allospecies.

Eviatar Nevo and his colleagues at the Institute of Evolution at the University of Haifa have studied this remarkable pattern for nearly 40 years. Four allospecies occur in Israel, distinguished by increasing numbers of chromosomes $(2 n=52,54,58$ and 60$)$ in the increasingly arid climate towards the east and south. Each allospecies is adapted to its home area, as established by painstaking physiological analysis. This work led to the publication of a book, Mosaic Evolution of Subterranean Mammals (Oxford University Press, 1999).

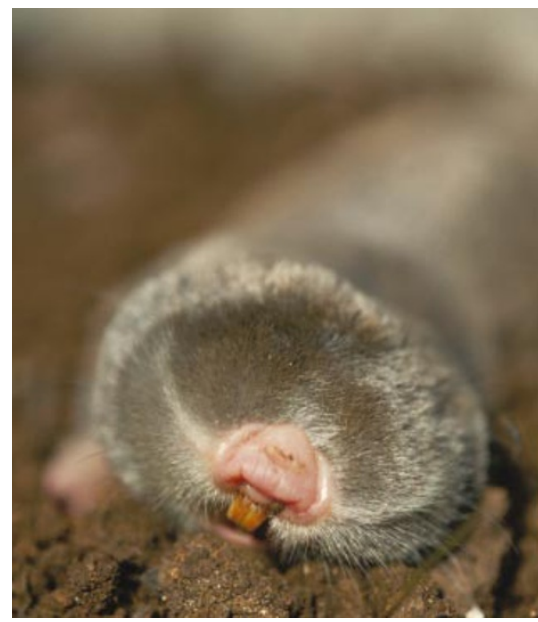

Underground evolution: the blind subterranean mole rat is remarkably well adapted to its habitat.

The same team has now published another book that deals with the origins of the unique population structure of $S$. ehrenbergi. Nevo and colleagues have focused on two questions: what peculiar process of speciation led to the extraordinary mosaic pattern of distribution of the 12 allospecies? And why is the adaptation to the gradually changing climate not gradual but stepwise, along the lines of changing chromosome number?

The answer to the first question is that speciation takes place by peripatric speciation in small, peripherally isolated founder populations - the founder effect means that, because the population represents only a small part of the total gene pool, it soon becomes genetically distinct. It can establish contact with the parent species only after the isolating mechanisms have been perfected.

The second question has a more remarkable answer. It turns out that each allospecies is adapted not only to the subterranean mode of life, but also to the particular external environment (climate) where it lives. This adaptation is in part gradual, like the climatic change, but also occurs in steps marked by chromosomal rearrangements, suggesting a remarkable cohesion of the genotype, reorganized by each bout of peripatric chromosomal speciation.
Nevo's admirably thorough analyses of numerous populations, both closely and more distantly related, shed light on such controversial subjects as function, origin and adaptationist programmes. This work is a model of modern population analysis. Ernst Mayr is at the Museum of Comparative Zoology, Harvard University, Cambridge, Massachusetts 02138, USA

\section{Trying to figure it out}

\section{The Millennium Problems: The Seven Greatest Unsolved} Mathematical Puzzles of Our Time by Keith Devlin

Basic Books: 2002. 256 pp. \$26, 118.99

\section{Jeremy Gray}

The millennium problems of the title are seven mathematical puzzles proposed in 2000 for solution by the Clay Mathematics Institute in Cambridge, Massachusetts. They are drawn from different areas of mathematics, and each carries a prize of US\$1 million for whoever solves it. While some might wish to see other problems in their place, or at least funded to the same extent, no one would dispute their importance, or deny that a solution would be a significant advance in mathematics. Such is their difficulty and importance that the widely distributed joke is that most mathematicians would pay a million dollars to be able to solve one of them.

To take them in the order they are given here, the first is the Riemann hypothesis, which concerns the distribution of prime numbers. The second asks for a rigorous mathematical theory of the Yang-Mills equations in particle physics, which are capable of establishing some of the key beliefs of physicists about mass. Problem three is about the complexity of problems solved by computers. Number four is about the mathematical equations governing fluid flow, which are still essentially unsolved.

The fifth problem is about a conjecture

\title{
Seminal Nature in Japanese
}

\section{Chi No Rekishi}

\section{(Knowledge From Nature)}

Just published in Japanese, by Tokuma Shoten, Tokyo, is a collection of Nature papers describing 21 significant scientific advances of the twentieth century. Each paper is accompanied by an illustrated essay by a luminary in the field concerned, placing the development in context. The collection is topped and tailed by announcements of the discovery of Australopithecus africanus in 1925 and the cloning of Dolly the sheep in 1997. In between, among other notable events, are the discoveries of the neutron, nuclear fission, seafloor spreading, pulsars, T-cell restriction, buckminsterfullerene and extrasolar planets. There is also a proposed structure for DNA from 1953 that has stood the test of time. The book is entitled Chi No Rekishi (Knowledge From Nature) and is edited by Laura Garwin and Tim Lincoln. It will appear in English next year. 
that certain basic methods of algebraic topology can unfailingly recognize a (threedimensional) sphere - curiously, the problem has been solved in all other dimensions. The sixth is about a remarkable conjecture in algebraic number theory, not far from the circle of ideas that led Andrew Wiles and Richard Taylor to the solution of Fermat's Last Theorem. The final problem returns to algebraic topology, but with a more technical question about the closeness or otherwise of algebraic and geometric ideas in versions of that theory. These last three are harder to 'sell' to a broad audience, but they each point to something quite specific in a major branch of mathematics which for some profound reason we do not understand.

I believe that mathematics should set out its stall in the way that the Clay Mathematics Institute has done, but it would be a valuable educational task to make mathematics graduates aware of what these problems say. The longer accounts of each problem on the Clay Mathematics Institute website (http://www. claymath.org/index.htm) presume a considerable amount of background knowledge.
But the problem of exposition is much more acute when, as Devlin has done, the decision is to aim for the largest audience possible.

Devlin's solution was to write a very elementary chapter on each problem, sometimes with a slightly harder set of short appendices. The result is a series of superficial remarks largely intelligible to schoolchildren over 16 , followed by a selection of more insightful remarks, followed by some vigorous hand-waving in the direction of the summit. These last are often of a motivational kind, supported by loosely accurate historical remarks, and aimed at amplifying the claim that the problems matter. The quality of the mathematical exposition is high, a sense of excitement is strongly conveyed, and the summits are at least glimpsed while the difficulties in approaching them remain rightly shrouded in mist. There will be other books, by other authors, aimed at readers who already know more mathematics.

Devlin has grappled openly and honestly with the problems of reaching his chosen audience. He is frank in admitting that it is easier to hint at some of the problems than others, and this accounts not only for the order in which he presents the problems but the sort of things he says about them. Full marks for trying. I hope, however, that readers of Nature will find this book too easy and want to read something deeper. It would be a poor reflection on scientists' education if they did not, and worse if they could not.

But I hope that bright, mathematically inclined school children will read this book and turn to mathematics. They might even go on to solve one of these problems, which would be magnificent. Even if all seven problems are eventually solved, mathematics contains many more problems that are at least as intellectually rewarding.

Jeremy Gray is at the Centre for the History of the Mathematical Sciences, Open University,

Milton Keynes MK7 6AA, UK.

\section{More on mathematics \\ Dr Riemann's Zeros: The Search for the $\$ 1$ million Solution to the Greatest Problem in Mathematics}

by Karl Sabbagh

Atlantic Books, $£ 14.99$

\section{Science in culture}

\section{A physical response to architecture}

Two Swiss architects design rooms to change your hormone levels.

Alison Abbott

Architecture is about space and light, usually considered in the abstract. But Swiss architects Philippe Rahm and Jean-Gilles Décosterd are fascinated with how the these properties affect us physically. In a series of projects over the past four years, they have examined the relationship between the external environment and human physiology, for example by modifying the composition of the air, or the wavelength of the light, that fills their architectonic space. They are aware that this is bringing architecture to an ethical crossroads.

This year they were selected to represent Switzerland at the Eighth International Architecture Exhibition at the La Biennale de Venezia, which closed recently, for which they designed their 'Hormonorium. Fittingly, the Hormonorium transports a high-Alpine environment to sea level, in much the same way that an urban swimming pool might be considered to be bringing the environment of a lake into a city.

The Hormonorium is a plain white room containing four white sofas. The visitor enters through a system of air-tight double doors. The floor of the room is imbedded with long rows of bright, full-spectrum fluorescent lights. Lit from below, the extreme brightness of the room evokes the snow-reflected light on a mountain-top on a sunny day. The ultraviolet part of the spectrum tans the skin, the infrared part could burn it. The level of oxygen in the air is reduced from the normal $21 \%$ at sea level to just $14.5 \%$, as it would 3,000 metres up a mountain. After 10 minutes, the visitor experiences the pleasant lightheadedness that accompanies a successful climb.

Playing further with the invisible parameters of the environment, the architects fill the room with 'music' of such low frequency $(40-80 \mathrm{~Hz})$ that it is felt through vibration, rather than heard. Visitors must wear blue plastic overshoes that crunch on the glass floor, adding to the sensation of being surrounded by snow.

The Hormonorium is so-called because the low-oxygen environment raises levels of erythropoetin, a hormone that stimulates the production of red blood cells, at least after a few hours. This is the basis of high-altitude training, where athletes train in the mountains to pump up the concentration of their red blood cells, so they can use oxygen more efficiently during a race.

This is not the architects' first engagement with hormone manipulation. Their 'Melatonin Room', exhibited last year at the San Francisco Museum of Modern Art, was alternately filled with an intense green light and a weak ultraviolet light, which suppress the production of the sleep hormone melatonin to different degrees. But if all this sounds like installation art rather than architecture, Rahm would disagree. He considers himself an architect first and foremost: "I want to work in the real world," he says.

Together with Décosterd, Rahm is designing a 'winter house', commissioned by a French artist and to be built near France's Atlantic coast. The house recreates a tropical environment in a very

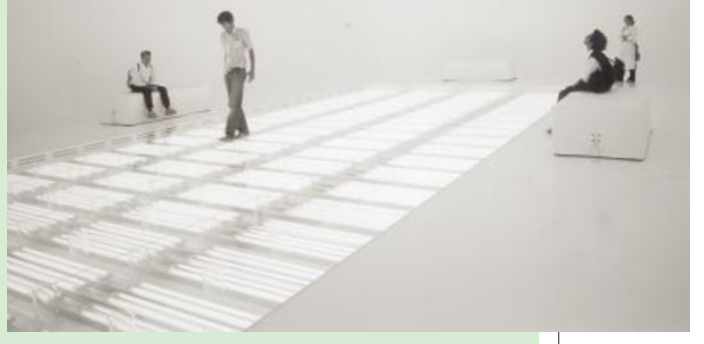

Mountain high: the Hormonorium's Alpine oxygen level boosts erythropoetin production.

literal way. The lighting will mimic, in intensity and timing, the natural day-and-night cycle of French Polynesia. The air will be as warm and moist as in Tahiti - and also just as scented, because the room that heats the house's circulating air will be packed with Tahitian plants. With its sealed and dislocated environment, the house will be used for just a few winter days at a time.

Rahm and Décosterd are moving ahead faster on the philosophical, rather than the practical, front with their physiological architecture. "There are ethical barriers to the wide use of architecture to modulate mood," says Rahm. Alison Abbott is Nature's senior European correspondent. 